\title{
Antimicrobial nanospheres thin coatings prepared by advanced pulsed laser technique
}

\author{
Alina Maria Holban ${ }^{1}$, Valentina Grumezescu ${ }^{2,3}$, \\ Alexandru Mihai Grumezescu² ${ }^{*}$, Bogdan Ştefan Vasile ${ }^{2}$, Roxana Truşcă ${ }^{4}$, \\ Rodica Cristescu ${ }^{3}$, Gabriel Socol ${ }^{3}$ and Florin lordache ${ }^{5}$
}

\section{Full Research Paper}

\section{Address:}

${ }^{1}$ University of Bucharest, Faculty of Biology, Microbiology

Department, Aleea Portocalelor no 1-3, 060101 Bucharest, Romania,

2University Politehnica of Bucharest, Faculty of Applied Chemistry and Materials Science, Department of Science and Engineering of Oxide Materials and Nanomaterials, Polizu Street no 1-7, 011061 Bucharest, Romania, ${ }^{3}$ National Institute for Lasers, Plasma \& Radiation Physics, Lasers Department, P.O.Box MG-36, Bucharest-Magurele, Romania, ${ }^{4}$ S.C. Metav-CD S.A., 31 Rosetti Str., 020015 Bucharest, Romania and ${ }^{5}$ Flow Cytometry and Cell Therapy Laboratory, Institute of Cellular Biology and Pathology "Nicolae Simionescu" (ICBP), Bucharest, Romania

\section{Email:}

Alexandru Mihai Grumezescu* - grumezescu@yahoo.com

* Corresponding author

Keywords:

antimicrobial; chitosan; magnetite nanoparticles; nanospheres;

$P$. aeruginosa; polylactic acid; $S$. aureus

\author{
Beilstein J. Nanotechnol. 2014, 5, 872-880. \\ doi:10.3762/bjnano.5.99 \\ Received: 21 January 2014 \\ Accepted: 11 May 2014 \\ Published: 18 June 2014 \\ Associate Editor: P. Ziemann \\ (๖ 2014 Holban et al; licensee Beilstein-Institut. \\ License and terms: see end of document.
}

\begin{abstract}
We report on the fabrication of thin coatings based on polylactic acid-chitosan-magnetite-eugenol (PLA-CS-Fe $\mathrm{O}_{4} @ \mathrm{EUG}$ nanospheres by matrix assisted pulsed laser evaporation (MAPLE). Transmission electron microscopy (TEM) and scanning electron microscopy (SEM) investigation proved that the homogenous $\mathrm{Fe}_{3} \mathrm{O}_{4} @$ EUG nanoparticles have an average diameter of about $7 \mathrm{~nm}$, while the PLA-CS-Fe $\mathrm{O}_{4} @$ EUG nanospheres diameter sizes range between 20 and $80 \mathrm{~nm}$. These MAPLE-deposited coatings acted as bioactive nanosystems and exhibited a great antimicrobial effect by impairing the adherence and biofilm formation of Staphylococcus aureus (S. aureus) and Pseudomonas aeruginosa (P. aeruginosa) bacteria strains. Moreover, the obtained nano-coatings showed a good biocompatibility and facilitated the normal development of human endothelial cells. These nanosystems may be used as efficient alternatives in treating and preventing bacterial infections.
\end{abstract}




\section{Introduction}

Driven by more and more microbial antibiotic resistance, alternative therapeutic approaches are emerging [1-4]. Polar and nonpolar, functionalized and non-functionalized magnetite nanostructures have proven successfully in combating microbial infections both in vitro and in vivo [5,6]. In the past years a series of papers have been published in prestigious journals highlighting the relevance of magnetite nanostructures in preventing the development of microbial biofilm and the opportunity of utilizing these nanosystems to obtain improved, antimicrobial coatings for biomedical applications [7,8]. Nonpolar functionalized magnetite nanostructures alone $[9,10]$ or combined with different natural products, such as usnic acid (UA) [11] or essential oils (Mentha piperita [12], Anethum graveolens [13], Salvia officinalis [14], Eugenia carryophyllata [15]), showed improved antibiofilm effects on different types of microbial strains. Usually, these types of phyto-nano-coatings have been applied to a variety of medical surfaces in order to improve their resistance to microbial colonization [16].

Matrix assisted pulsed laser evaporation (MAPLE) processing has been applied to overcome several drawbacks of conventional solvent-based deposition techniques, such as inhomogeneous films, inaccurate placement of material, and difficult or erroneous thickness control $[17,18]$. MAPLE has been used to obtain thin films and coatings of soft materials, organic and polymeric materials, and complex molecules [19-35].

Furthermore, the compatibility of MAPLE processing has been demonstrated for inorganic systems such as $\mathrm{TiO}_{2}$ [36], and $\mathrm{Fe}_{3} \mathrm{O}_{4}$ nanoparticle-based materials [37], metaloporphyrines [38] and for biomolecules, e.g., poly(lactic acid) (PLA) [39], poly(lactic-co-glycolic acid) PLGA [40], polyvinyl alcohol (PVA) [41] and fibrinogen [42].

Our recent reports have highlighted the capability of the laser processing technique to prepare thin coatings based on polymeric microspheres. Thus, Socol et al., [43], firstly reported the novel deposition of PLGA-PVA, PLGA-PVA-BSA (bovine serum albumin) and PLGA-PVA-CS microspheres by matrix assisted pulsed laser evaporation (MAPLE) technique. SEM images of thin coatings reveal homogeneous and sphericalshaped particles in the micrometric range. The average diameter of PLGA-PVA, PLGA-PVA-BSA (bovine serum albumin) and PLGA-PVA-CS particles ranged from 180 to $250 \mathrm{~nm}$. Grumezescu et al., [34], reported the MAPLE fabrication of PLA-PVA-UA microsphere thin coatings. These thin coatings possessed a homogeneous shape and showed no concavities or distortions on their surface within an average diameter of $1 \mu \mathrm{m}$ of the deposited spheres. It is noteworthy that the microspheres maintain their initial size and do not show an aggregative behavior [34]. All these type of microspheres have been prepared by an oil-in-water emulsion-diffusion-evaporation method.

Here, we report the fabrication of thin coatings based on magnetic PLA-CS- $\mathrm{Fe}_{3} \mathrm{O}_{4} @$ EUG nanospheres with an average diameter of the deposed spheres between 20 and $80 \mathrm{~nm}$. This is the first study that reports the MAPLE processing of thin coatings containing spheres with a diameter of less than $100 \mathrm{~nm}$. The thin coating is composed of nanospheres based on magnetite nanostructures and biocompatible polymers. The thin coating also exhibited antibiofilm activity, thereby opening a new perspective for the prevention of medical surfaces infections.

\section{Materials and Methods Materials}

Polylactic acid (PLA), polyvinyl alcohol (PVA), chitosan (CS), eugenol (EUG), $\mathrm{FeCl}_{3}, \mathrm{FeSO}_{4} \cdot 7 \mathrm{H}_{2} \mathrm{O}, \mathrm{NH}_{4} \mathrm{OH}(25 \%)$, chloroform and $n$-hexane were purchased from Sigma-Aldrich.

\section{Preparation of magnetite nanostructures}

A well-known procedure described in our previous work was used to synthesize the magnetite nanostructures [44]. Briefly, EUG and $\mathrm{NH}_{4} \mathrm{OH}$ (25\%) were added in deionized water under vigorous stirring. Then, $\mathrm{FeCl}_{3}$ and $\mathrm{FeSO}_{4} \cdot 7 \mathrm{H}_{2} \mathrm{O}$ were dissolved in deionized water, and $\mathrm{Fe}^{2+} / \mathrm{Fe}^{3+}$ solution was dropped into the basic solution of EUG. After precipitation, magnetite-eugenol nanopowder $\left(\mathrm{Fe}_{3} \mathrm{O}_{4} @ \mathrm{EUG}\right)$ were repeatedly washed with methanol and separated with a strong $\mathrm{NdFeB}$ permanent magnet.

\section{Preparation of nanospheres}

PLA-CS-Fe $\mathrm{O}_{4} @$ EUG nanospheres were prepared by means of a solvent evaporation method [34,45]. Thus, 4 mL PLA/chloroform solution (10 wt \%) and $5 \mathrm{~mL}$ aqueous solution of PVA (2 wt \%), CS (10 wt \%) and $\mathrm{Fe}_{3} \mathrm{O}_{4} @$ EUG (1 wt \%) were emulsified with a SONIC-1200WT sonicator model from MRC for $6 \mathrm{~min}$, in ON/OFF steps of $5 \mathrm{~s}$ and $3 \mathrm{~s}$ with a limitation temperature of $\max 40^{\circ} \mathrm{C}$, followed by solvent evaporation in $100 \mathrm{~mL}$ deionized water with mechanical stirring at $1000 \mathrm{rpm}$. The prepared nanospheres were thoroughly washed with deionized water and then lyophilized. PLA-CS- $\mathrm{Fe}_{3} \mathrm{O}_{4} @$ EUG nanopheres were further used to deposit thin films by using the MAPLE technique.

\section{MAPLE thin coating deposition}

MAPLE targets were prepared by freezing them for $30 \mathrm{~min}$ at the temperature of liquid nitrogen using a suspension of $1.5 \%(\mathrm{w} / \mathrm{v})$ PLA-CS- $\mathrm{Fe}_{3} \mathrm{O}_{4} @$ EUG microspheres in $n$-hexane. 
The radiation of a $\mathrm{KrF}^{*}\left(\lambda=248 \mathrm{~nm}, \tau_{\mathrm{FWHM}}=25 \mathrm{~ns}\right)$ COMPexPro 205 Lambda Physics-Coherent excimer laser source model impinged the frozen targets at a laser fluence of $300-500 \mathrm{~mJ} / \mathrm{cm}^{2}$ and a repetition rate of $15 \mathrm{~Hz}$. In order to assure the reproducibility of the nanosphere thin film deposition, the energy distribution of the laser spot was improved by using a laser beam homogenizer. During the deposition, the target was rotated with $0.4 \mathrm{~Hz}$ to avoid target heating and subsequent drilling. All depositions were conducted at room temperature under $0.1 \mathrm{~Pa}$ background pressure and a target-substrate separation distance of $4 \mathrm{~cm}$ by applying 45,000-160,000 subsequent laser pulses. During deposition, the MAPLE target was kept at low temperature by continuous liquid nitrogen cooling. The coatings were deposited onto glass, both sides polished (100) silicon for IRM, SEM, and biological assays. Prior to placing the substrates inside the deposition chamber, they were cleaned in an ultrasonic bath with acetone, ethanol and deionized water for $15 \mathrm{~min}$, and then dried in a jet of high purity nitrogen.

\section{Characterization}

\section{Transmision electron microscopy}

The transmission electron microscopy (TEM) images were obtained on finely powdered samples by using a Tecnai ${ }^{\mathrm{TM}} \mathrm{G} 2$ F30 S-TWIN high resolution transmission electron microscope manufactured by FEI Company (OR, USA). The microscope operated in transmission mode at $300 \mathrm{kV}$ with a TEM point resolution of $2 \AA$ and a line resolution of $1 \AA$. The prepared powder was dispersed into pure ethanol and ultrasonicated for $15 \mathrm{~min}$. After that, the diluted sample was poured onto a holey carbon-coated copper grid and left to dry before TEM analysis.

\section{Infrared Microscopy}

IR mappings were recorded on a Nicolet iN10 MX FT-IR Microscope with an MCT liquid nitrogen cooled detector in the measurement range 4000-600 $\mathrm{cm}^{-1}$. Spectral collection was carried out in reflection mode at $4 \mathrm{~cm}^{-1}$ resolution. For each spectrum, 32 scans were co-added and converted to absorbance by means of the OmincPicta software (Thermo Scientific). Approximately 600 spectra were analyzed for each coating and drop cast. Four absorptions peaks known as being characteristics for the PLA-CS-Fe ${ }_{3} \mathrm{O}_{4} @ E U G$ were selected as spectral markers for the presence of nanospheres in the prepared coatings.

\section{Scanning electron microscopy}

SEM analysis was performed on a FEI electron microscope by using secondary electron beams with energies of $30 \mathrm{keV}$ on samples covered with a thin gold layer.

\section{Cell viability}

Human endothelial cells (EAhy926 cell line, ATCC, USA) were grown in Dulbecco's Modified Eagle Medium (DMEM) culture medium containing 10\% Fetal Bovine Serum (FBS), and 1\% penicillin and neomycin (Sigma Aldrich, St. Louis, MO, USA). For cell proliferation and viability CellTiter96 Non-Radioactive Cell Proliferation Assay, (Promega, Madison, USA) was used. Endothelial cells were seeded in a 96-well plate at a density of $5 \times 10^{3}$ cells/well in DMEM medium, supplemented with $10 \% \mathrm{FBS}$, and incubated with nanospheres coated with eugenol for $72 \mathrm{~h}$. The controls were represented by endothelial cells grown under the same culture conditions, but on bare substrates. Following the guidelines of the manufacturer the cell proliferation assay was performed in triplicates at different time intervals. Briefly, $15 \mu \mathrm{L}$ of Promega Kit Solution I was added to each well and incubated for $4 \mathrm{~h}$. Furthermore, $100 \mu \mathrm{L}$ of Promega Kit Solution II was added to the 96-well plate and incubated for another hour. Spectrophotometry measurements were performed at $570 \mathrm{~nm}$ with a Mithras LB 940 spectrophotometer (Berthold Technology, Germany).

RED CMTPX fluorophore (Life Technologies, Invitrogen, USA) is a cell tracker for the long-term tracing of living cells. The RED CMTPX dye was added to the culture medium at a final concentration of $5 \mu \mathrm{M}$, incubated for $30 \mathrm{~min}$ so that the dye is able to penetrate the cells. The cells were washed with phosphate-buffered saline (PBS) and visualized by fluorescent microscopy. The nuclei were counterstained with a $1 \mathrm{mg} / \mathrm{mL}$ solution of 4',6-diamidino-2-phenylindole (DAPI). Living cells were traced in the presence of nanospheres for $5 \mathrm{~d}$ in culture. The micrographs were taken by a digital camera driven by the Axio-Vision 4.6 (Carl Zeiss, Germany) software.

\section{In vitro microbial biofilm development}

Staphylococcus aureus ATCC 25923 and Pseudomonas aeruginosa ATCC 27853 strains were purchased from American Type Cell Collection (ATCC, USA). For the biofilm assays, fresh bacteria cultures were obtained in Luria Broth. Bacteria cultures were subsequently diluted as mentioned below.

The biofilm formation was assessed by using 6 multi-well plates (Nunc) in a static model for monospecific biofilm development. Coated and uncoated glass substrates were distributed in the plates containing $2 \mathrm{~mL}$ of microbial inoculum diluted to $10^{4}-10^{5}$ colony forming units $/ \mathrm{mL}(\mathrm{CFU} / \mathrm{mL})$ in Luria Broth. Samples were incubated for $24 \mathrm{~h}$ at $37^{\circ} \mathrm{C}$. The biofilm formation was assessed after $24 \mathrm{~h}, 48 \mathrm{~h}$ and $72 \mathrm{~h}$ by a viable cell counts (VCC) assay [46].

After $24 \mathrm{~h}$ of incubation time, the culture medium was removed and the samples were washed with sterile PBS to remove the 
unattached bacteria. Coated and uncoated substrates were placed in fresh medium and incubated for an additional $24 \mathrm{~h}$, $48 \mathrm{~h}$ and $72 \mathrm{~h}$. After the incubation the samples were gently washed with sterile PBS to remove the non-adherent cells and placed in $1.5 \mathrm{~mL}$ micro-centrifuge tubes (Eppendorf) containing $750 \mu \mathrm{L}$ PBS. In order to disperse biofilm cells into the suspension, the samples were vigorously mixed by vortexing for $30 \mathrm{~s}$ and sonicated for $10 \mathrm{~s}$. Serial ten-fold dilutions were prepared and plated on Luria-Bertani (LB) agar for VCC. Experiments were performed in triplicate and repeated on three separate occasions $[12,47]$.

\section{Statistical analysis}

The statistical significance of the obtained results was analyzed by using GraphPad Prism version 5.04 for Windows, GraphPadSoftware, San Diego, CA, USA. For comparison, we used the number of CFU/mL as revealed by the readings of three values/ experimental variants. Two-way ANOVA and Tukey's multiple comparison tests were used for revealing significant differences among the analyzed groups.

\section{Results and Discussion}

The morphology and size of magnetite nanoparticles was analyzed by TEM. We confirmed the nanometric dimensions of used powder in order to prepare PLA-CS-Fe ${ }_{3} \mathrm{O}_{4} @ E U G$ nanospheres. TEM images of $\mathrm{Fe}_{3} \mathrm{O}_{4} @ E U G$ at different magnification (Figure 1) show that the prepared powder has a spherical shape with a narrow size distribution of approximately $7 \mathrm{~nm}$.

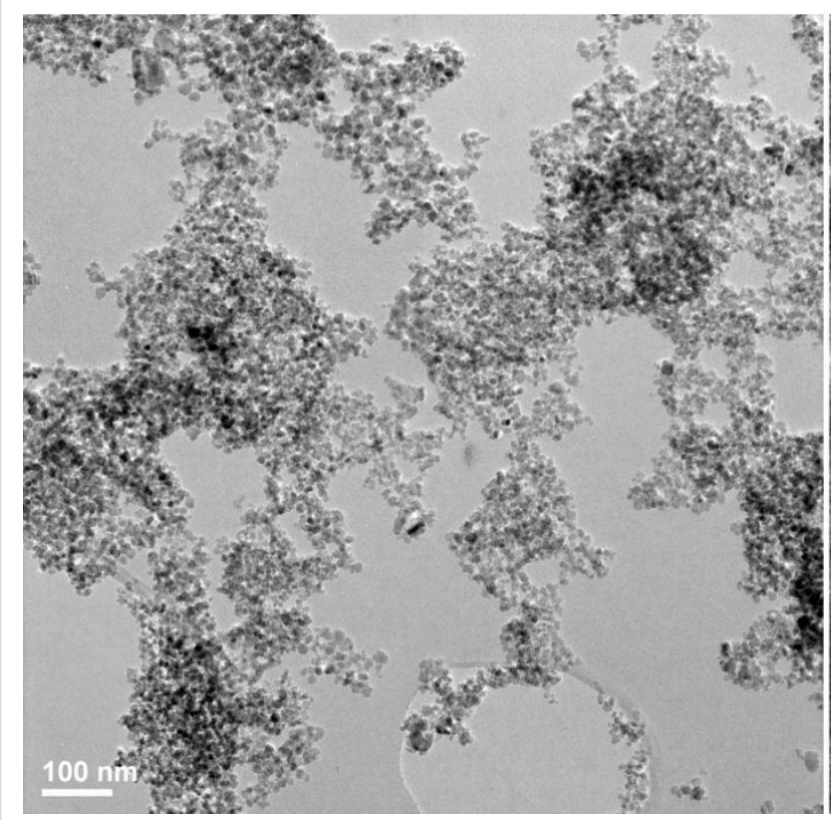

Infrared microscopy was used to demonstrate the integrity of functional groups after MAPLE processing. The visible spectrum images and infrared maps based on full spectral intensity of drop cast and MAPLE thin coatings overlain on the surface are plotted in Figure 2. The prepared polymeric spheres thin coatings are distributed on the entire surface of the substrate without any free spots as can be observed on the maps of drop cast (Figure $3 \mathrm{a}_{1}, \mathrm{~b}_{1}, \mathrm{c}_{1}$ and $\mathrm{d}_{1}$ ).

Figure 3 shows the second derivative infrared maps of PLA-CS-Fe $\mathrm{O}_{4} @$ EUG surfaces involved in this study. Second derivative infrared mapping is used to evaluate the structural integrity of samples [42]. Absorbance intensities of IR spectra maps commensurate with the color changes starting with blue (lowest intensity) and gradually increasing through green and yellow to red (highest intensity) [43]. 600 IR spectra were analyzed for each thin coating [34].

According to Figure 3 areas with moderate (green) and high intensity (red) of selected absorption bands can be observed. The tendency of nanospheres to form aggregates gives rise to the red areas. In the case of the drop cast maps, it can be concluded that there is no uniformity in the sampleand little high intensity can be observed. According to Figure 4, the thin films deposited by MAPLE $\left(F=300 \mathrm{~mJ} / \mathrm{cm}^{2}\right)$ revealed no degradation of functional groups during the laser processing.

The thin coatings deposited at $300 \mathrm{~mJ} / \mathrm{cm}^{2}$ laser fluence with an estimated average thickness of $(\approx 2 \mu \mathrm{m})$ were analyzed by SEM

Figure 1: TEM images of prepared $\mathrm{Fe}_{3} \mathrm{O}_{4} @ E U G$ nanoparticles.

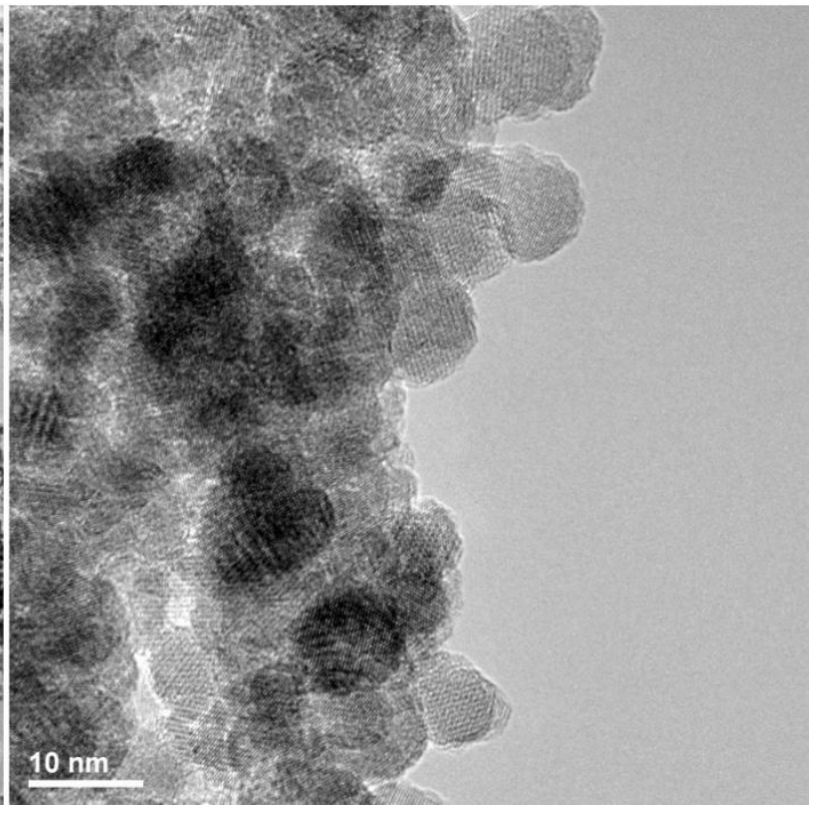




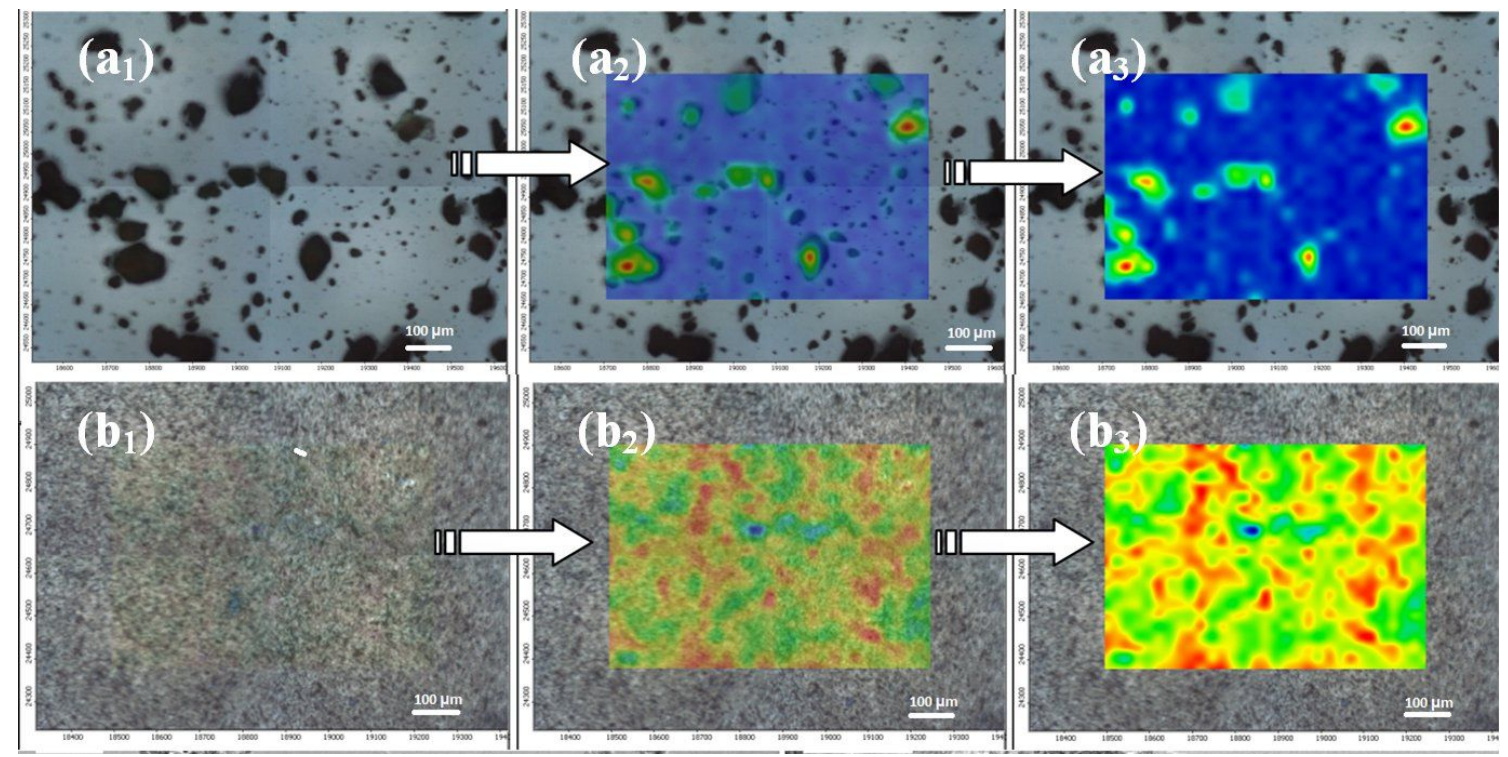

Figure 2: Full spectral intensity based on visible images and infrared maps of PLA-CS- $\mathrm{Fe}_{3} \mathrm{O}_{4} @ E$ EU drop cast (a) and PLA-CS-Fe $3 \mathrm{O}_{4} @ E$ EU MAPLE thin coatings (b) overlain on the surface.

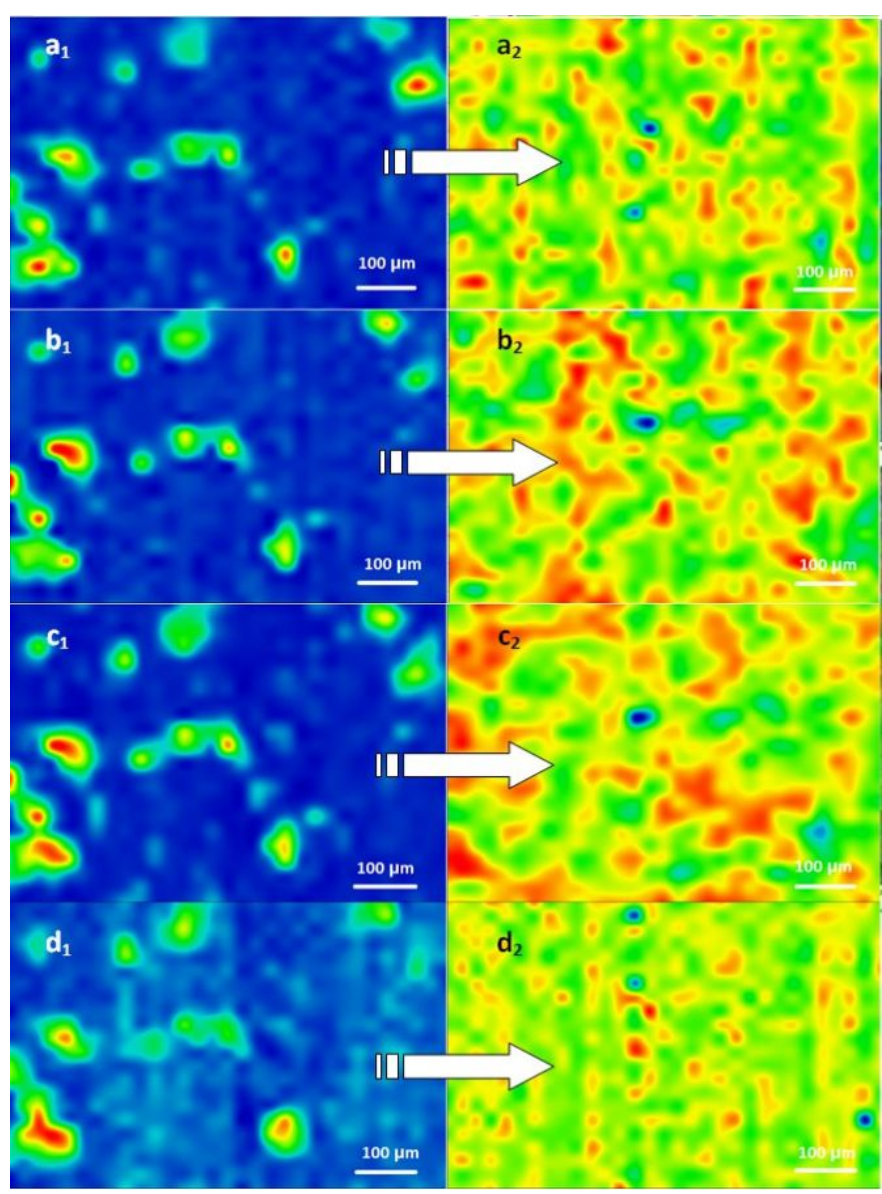

Figure 3: Second derivate IR mappings of the drop cast surface (1) and the thin coating $\left(F=300 \mathrm{~mJ} / \mathrm{cm}^{2}\right)$ surfaces (2). Intensity distributions are (a) $2954 \mathrm{~cm}^{-1}$ ( $\mathrm{CH}_{3}$ stretch), (b) $1739 \mathrm{~cm}^{-1}$ (C=O carbonyl group), (c) $1450 \mathrm{~cm}^{-1}$ (assigned to the lactides $-\mathrm{CH}_{3}$ group), and (d) $\approx 1182 \mathrm{~cm}^{-1}$ (-C-Obond stretching). 


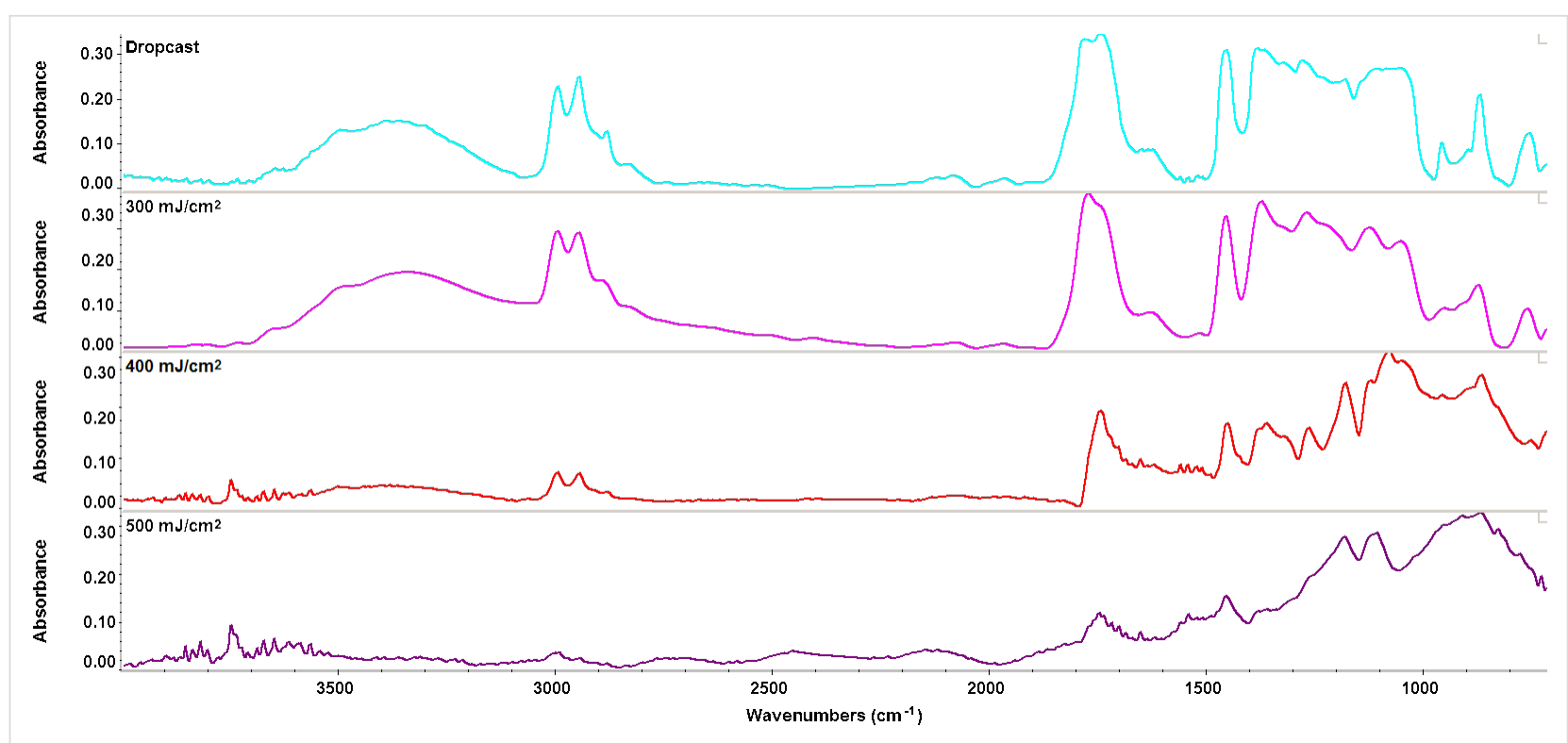

Figure 4: FTIR spectra of the drop cast surface and the thin coating surfaces $\left(F=300 / 400 / 500 \mathrm{~mJ} / \mathrm{cm}^{2}\right)$.

(Figure 5). It can be seen that the thin coatings contain higher numbers of nanospheres on top of their surfaces with diameters between 20 and $80 \mathrm{~nm}$. This is the first study that reports the MAPLE processing of thin coatings containing spheres with a diameter lower than $100 \mathrm{~nm}$. Previous studies have reported the MAPLE processing of thin coatings containing spheres with diameters within the range of $180-1,000 \mathrm{~nm}[34,38]$.

Cytotoxicity assays revealed that the prepared nano-coatings have a great biocompatibility, and support the growth of endothelial cell cultures. The cell tracker RED CMTPX fluo- rophore showed that the endothelial cells are viable and exhibit a normal grow and proliferation capacity in the presence of modified nano-coated bioactive surfaces. Furthermore, the cell monolayers developed on the thin coating surfaces have a normal morphology and architecture after five days of incubation (Figure 6).

Despite its good biocompatibility with human cells, the newly synthesized nano-active thin coating exhibited a great antimicrobial activity. The surface inhibited both $S$. aureus and $P$. aeruginosa attachment and also the formation of non-specific

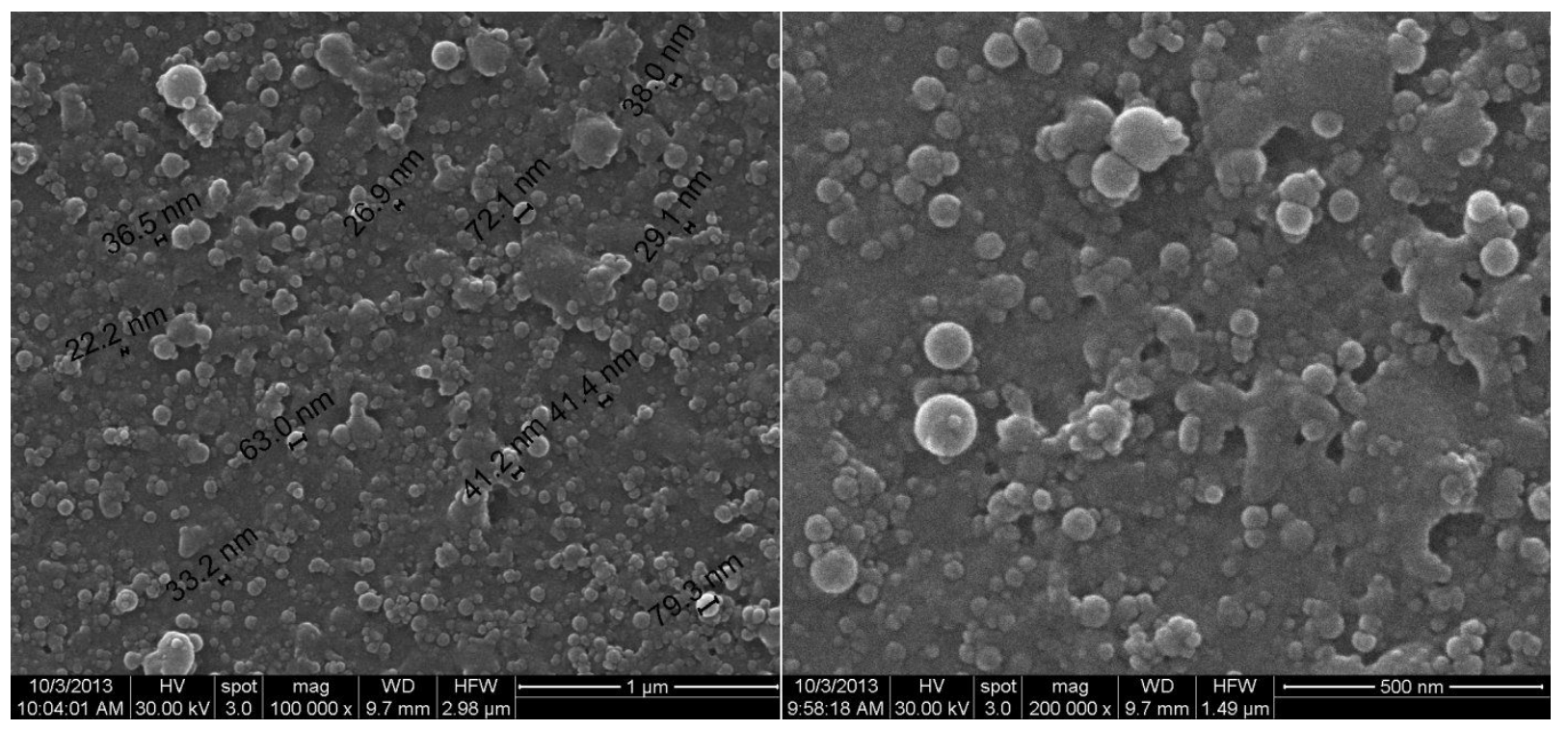

Figure 5: SEM images of nanosphere thin coatings prepared by MAPLE at different magnifications. 


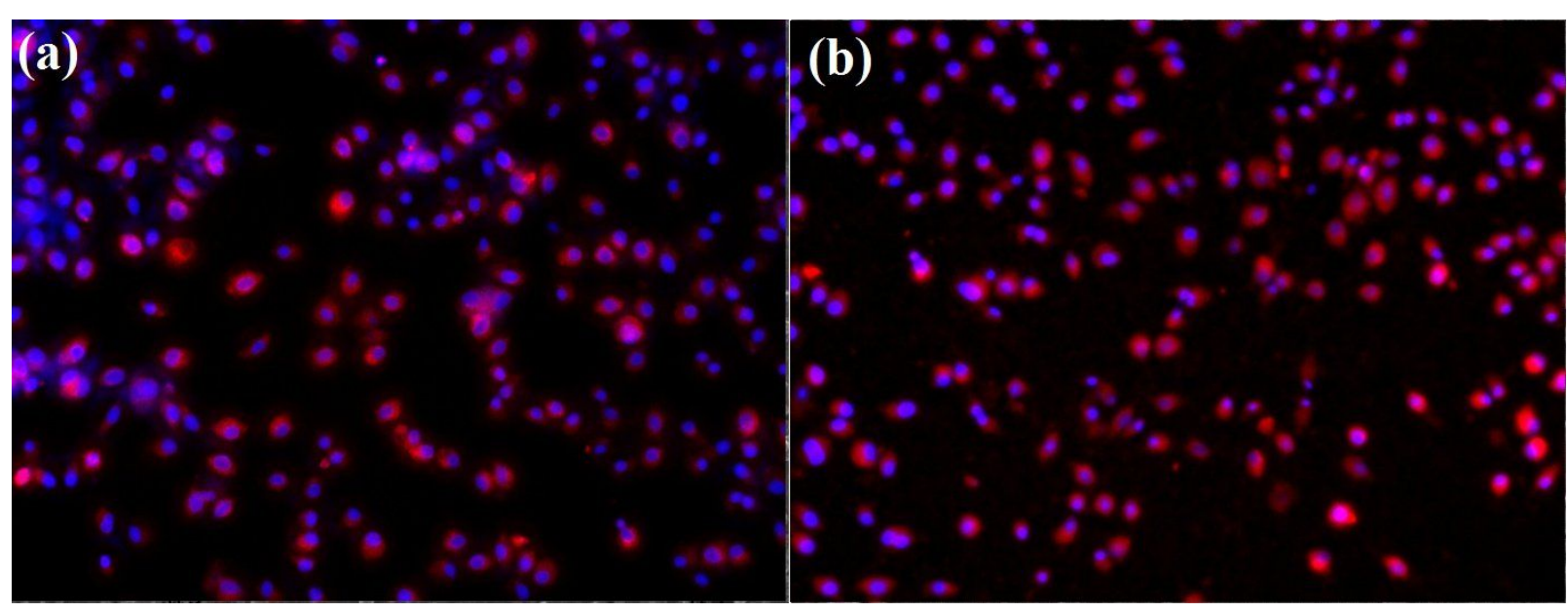

Figure 6: Human endothelial cells (EAhy926 cell line) after five days of growth on (a) control surface and (b) MAPLE coated surfaces.

biofilms. MAPLE deposited thin films interfere with biofilm formation both in the initial phase and during biofilm maturation. S. aureus (Figure 7) biofilms were significantly impaired at all tested points of time, while $P$. aeruginosa (Figure 8) biofilms are especially affected after 24 and $48 \mathrm{~h}$ of incubation.

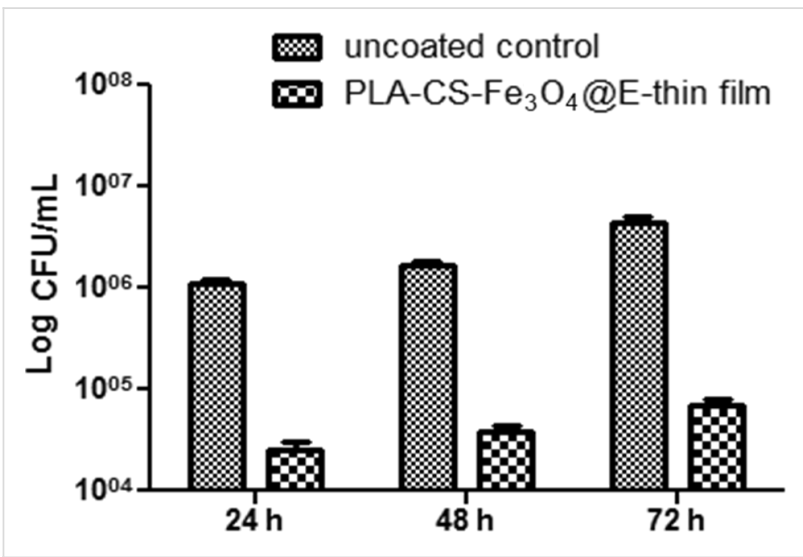

Figure 7: Graphic representation of viable cell count analysis after removal of $S$. aureus biofilm embedded cells $24 \mathrm{~h}, 48 \mathrm{~h}$ and $72 \mathrm{~h}$ postinfection (PLA-CS-Fe $\mathrm{O}_{4} @ E$ EU thin film coatings vs uncoated control; $\mathrm{CFU} / \mathrm{mL}=$ colony forming units $/ \mathrm{mL}$ ).

Even though magnetite nanoparticles displayed a great antimicrobial effect, many studies reported that these nanostructures may be highly toxic for hosts in higher concentrations or even active doses [48-50]. Our results demonstrate that the novel synthesized PLA-CS-Fe ${ }_{3} \mathrm{O}_{4} @$ EUG complex nanosystems combine the proven efficacy of $\mathrm{Fe}_{3} \mathrm{O}_{4}$ and eugenol [40] with the biocompatibility and biodegradability of PLA and CS polymers resulting in a novel safe nanobiocomposite. Due to these characteristics PLA-CS-Fe $\mathrm{O}_{4} @$ EUG thin films represent a competitive candidate for the development of novel biomedical surfaces or devices with low costs and a high efficiency.

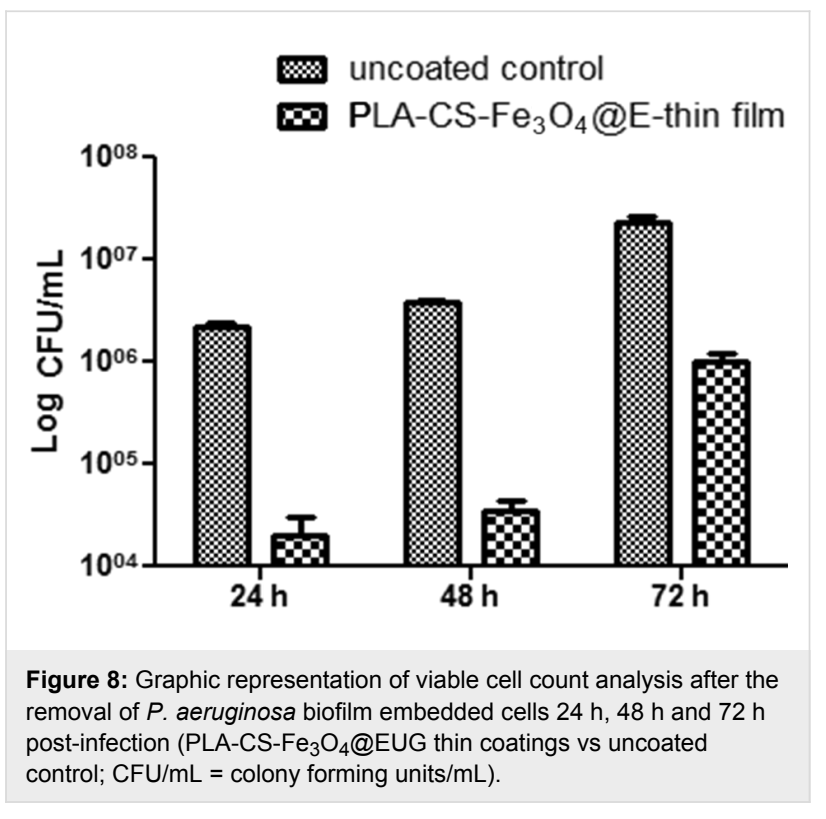

\section{Conclusion}

This paper reports the successful MAPLE deposition of bioactive thin films based on PLA-CS-Fe ${ }_{3} \mathrm{O}_{4} @$ EUG magnetic nanospheres with diameters between 20 and $80 \mathrm{~nm}$. These nanocoatings displayed great antimicrobial colonization and antibiofilm formation properties, inhibiting $S$. aureus and $P$. aeruginosa biofilms. Due to the biocompatibility of this material it as a suitable candidate in developing nanostructured bioactive materials for biomedical applications.

\section{Acknowledgements}

This paper is supported by the Sectorial Operational Programme Human Resources Development, financed from the European Social Fund, and by the Romanian Government under the contract number ID 132397 (ExcelDOC). Also, by the 
Romanian National Authority for Scientific Research, CNCSUEFISCDI, projects no. PCCA 153/02.07.2012 and PN-II-IDPCE-2011-3-0888 (209/5.10.2011).

\section{References}

1. Nafee, N.; Youssef, A.; El-Gowelli, H.; Asem, H.; Kandil, S. Int. J. Pharm. 2013, 454, 249-258. doi:10.1016/j.ijpharm.2013.06.067

2. Grumezescu, A. M.; Andronescu, E.; Holban, A. M.; Ficai, A.; Ficai, D.; Voicu, G.; Grumezescu, V.; Balaure, P. C.; Chifiriuc, C. M. Int. J. Pharm. 2013, 454, 233-240. doi:10.1016/j.ijpharm.2013.06.054

3. Voicu, G.; Grumezescu, V.; Andronescu, E.; Grumezescu, A. M.; Ficai, A.; Ficai, D.; Ghitulica, C. D.; Gheorghe, I.; Chifiriuc, M. C. Int. J. Pharm. 2013, 446, 63-69. doi:10.1016/j.ijpharm.2013.02.011

4. Balaure, P. C.; Andronescu, E.; Grumezescu, A. M.; Ficai, A.; Huang, K.-S.; Yang, C.-H.; Chifiriuc, C. M.; Lin, Y.-S. Int. J. Pharm. 2013, 441, 555-561. doi:10.1016/j.ijpharm.2012.10.045

5. Saviuc, C.; Grumezescu, A. M.; Chifiriuc, M. C.; Bleotu, C.; Stanciu, G.; Hristu, R.; Mihaiescu, D. E.; Lazar, V. Biointerface Res. Appl. Chem. 2011, 1 (1), 31-40.

6. Saviuc, C.; Grumezescu, A. M.; Bleotu, C.; Holban, A.; Chifiriuc, C.; Balaure, P.; Lazar, V. Biointerface Res. Appl. Chem. 2011, 1 (3), 111-118.

7. Shekoufeh, B.; Azhar, L.; Lotfipour, F. Pharmazie 2012, 67, 817-821. doi:10.1691/ph.2012.1163

8. Marková, Z.; Šišková, K.; Filip, J.; Šafářová, K.; Prucek, R.; Panáček, A.; Kolář, M.; Zbořil, R. Green Chem. 2012, 14, 2550-2558. doi:10.1039/c2gc35545k

9. Chifiriuc, M. C.; Grumezescu, A. M.; Saviuc, C.; Hristu, R.; Grumezescu, V.; Bleotu, C.; Stanciu, G.; Mihaiescu, D. E.; Andronescu, E.; Lazar, V.; Radulescu, R. Curr. Org. Chem. 2013, 17, 1023-1028. doi:10.2174/1385272811317100004

10. Anghel, I.; Grumezescu, A. M.; Andronescu, E.; Anghel, A. G.; Ficai, A.; Saviuc, C.; Grumezescu, V.; Vasile, B. S.; Chifiriuc, M. C. Nanoscale Res. Lett. 2012, 7, 501. doi:10.1186/1556-276X-7-501

11. Grumezescu, A. M.; Saviuc, C.; Chifiriuc, C. M.; Hristu, R.; Mihaiescu, D. E.; Balaure, P.; Stanciu, G.; Lazar, V. IEEE Trans. NanoBioscience 2011, 10, 269-274. doi:10.1109/TNB.2011.2178263

12. Anghel, I.; Grumezescu, A. M. Nanoscale Res. Lett. 2013, 8, 6. doi:10.1186/1556-276X-8-6

13. Anghel, I.; Holban, A. M.; Andronescu, E.; Grumezescu, A. M.; Chifiriuc, M. C. Biointerphases 2013, 8, 12. doi:10.1186/1559-4106-8-12

14. Anghel, I.; Grumezescu, V.; Andronescu, E.; Anghel, G. A.; Grumezescu, A. M.; Mihaiescu, D. E.; Chifiriuc, M. C. Dig. J. Nanomater. Bios. 2012, 7, 1205-1212.

15. Grumezescu, A. M.; Chifiriuc, M. C.; Saviuc, C.; Grumezescu, V.; Hristu, R.; Mihaiescu, D. E.; Stanciu, G. A.; Andronescu, E. IEEE Trans. NanoBioscience 2012, 11, 360-365. doi:10.1109/TNB.2012.2208474

16. Holban, A. M.; Grumezescu, A. M.; Gestal, M. C.; Mogoanta, L.; Mogosanu, G. D. Curr. Org. Chem. 2014, 18, 185-191. doi:10.2174/13852728113176660142

17. McGill, R. A.; Chrisey, D. B. US Patent 6025036 A Feb 15, 2000.

18. Cristescu, R.; Popescu, C.; Socol, G.; Visan, A.; Mihailescu, I. N.; Gittard, S. D.; Miller, P. R.; Martin, T. N.; Narayan, R. J.; Andronie, A.; Stamatin, I.; Chrisey, D. B. Appl. Surf. Sci. 2011, 257, 5287-5292. doi:10.1016/j.apsusc.2010.11.141
19. Chrisey, D. B.; Piqué, A.; McGill, R. A.; Horwitz, J. S.; Ringeisen, B. R.; Bubb, D. M.; Wu, P. K. Chem. Rev. 2003, 103, 553-576. doi:10.1021/cr010428w

20. Toftmann, B.; Papantonakis, M. R.; Auyeung, R. C. Y.; Kim, W.; O'Malley, S. M.; Bubb, D. M.; Horwitz, J. S.; Schou, J.; Johansen, P. M.; Haglund, R. F., Jr. Thin Solid Films 2004, 453-454, 177-181. doi:10.1016/j.tsf.2003.11.099

21. Gutiérrez-Llorente, A.; Horowitz, G.; Pérez-Casero, R.; Perrière, J.; Fave, J. L.; Yassar, A.; Sant, C. Org. Electron. 2004, 5, 29-34. doi:10.1016/j.orgel.2003.11.003

22. Fitz-Gerald, J. M.; Jennings, G.; Johnson, R.; Fraser, C. L. Appl. Phys. A 2005, 80, 1109-1112. doi:10.1007/s00339-003-2392-1

23. Fryček, R.; Jelínek, M.; Kocourek, T.; Fitl, P.; Vrňata, M.; Myslík, V.; Vrbová, M. Thin Solid Films 2006, 495, 308-311. doi:10.1016/j.tsf.2005.08.178

24. György, E.; Santiso, J.; Figueras, A.; Socol, G.; Mihailescu, I. N. J. Mater. Sci.: Mater. Med. 2007, 18, 1643-1647. doi:10.1007/s10856-007-3055-0

25. Jelinek, M.; Remsa, J.; Brynda, E.; Houska, M.; Kocourek, T. Appl. Surf. Sci. 2007, 254, 1240-1243. doi:10.1016/j.apsusc.2007.07.159

26. Purice, A.; Schou, J.; Kingshott, P.; Dinescu, M. Chem. Phys. Lett. 2007, 435, 350-353. doi:10.1016/j.cplett.2006.12.078

27. Hunter, C. N.; Check, M. H.; Bultman, J. E.; Voevodin, A. A. Surf. Coat. Technol. 2008, 203, 300-306. doi:10.1016/j.surfcoat.2008.09.003

28. Johnson, S. L.; Park, H. K.; Haglund, R. F., Jr. Appl. Surf. Sci. 2007, 253, 6430-6434. doi:10.1016/j.apsusc.2007.01.084

29. Negroiu, G.; Piticescu, R. M.; Chitanu, G. C.; Mihailescu, I. N.; Zdrentu, L.; Miroiu, M. J. Mater. Sci.: Mater. Med. 2008, 19, 1537-1544. doi:10.1007/s10856-007-3300-6

30. Martino, M.; Caricato, A. P.; Romano, F.; Tunno, T.; Valerini, D.; Anni, M.; Caruso, M. E.; Romano, A.; Verri, T. J. Mater. Sci.: Mater. Electron. 2009, 20, S435-S440. doi:10.1007/s10854-008-9663-8

31. Pate, R.; Lantz, K. R.; Stiff-Roberts, A. D. IEEE J. Sel. Top. Quantum Electron. 2008, 14, 1022-1030. doi:10.1109/JSTQE.2008.915625

32. Riggs, B. C.; Dias, A. D.; Schiele, N. R.; Cristescu, R.; Huang, Y.; Corr, D. T.; Chrisey, D. B. MRS Bull. 2011, 36, 1043-1050. doi:10.1557/mrs.2011.276

33. Cicco, N.; Morone, A.; Verrastro, M.; Viggiano, V. Appl. Surf. Sci. 2013, 278, 223-225. doi:10.1016/j.apsusc.2012.12.056

34. Darwish, A. M.; Sagapolutele, M. T.; Sarkisov, S.; Patel, D.; Hui, D.; Koplitz, B. Composites, Part B 2013, 55, 139-146. doi:10.1016/j.compositesb.2013.06.013

35. Chen, C. J.; Lai, C. C.; Tseng, M. C.; Liu, Y. C.; Lin, S. Y.; Tsai, F. J. Anal. Chim. Acta 2013, 783, 31-38. doi:10.1016/j.aca.2013.04.029

36. Caricato, A. P.; Capone, S.; Ciccarella, G.; Martino, M.; Rella, R.; Romano, F.; Spadavecchia, J.; Taurino, A.; Tunno, T.; Valerini, D. Appl. Surf. Sci. 2007, 253, 7937-7941. doi:10.1016/j.apsusc.2007.02.066

37. Cristescu, R.; Popescu, C.; Socol, G.; lordache, I.; Mihailescu, I. N.; Mihaiescu, D. E.; Grumezescu, A. M.; Balan, A.; Stamatin, I.; Chifiriuc, C.; Bleotu, C.; Saviuc, C.; Popa, M.; Chrisey, D. B. Appl. Surf. Sci. 2012, 258, 9250-9255. doi:10.1016/j.apsusc.2012.02.055 
38. Cristescu, R.; Popescu, C.; Popescu, A. C.; Mihailescu, I. N.; Ciucu, A. A.; Andronie, A.; lordache, S.; Stamatin, I.; Fagadar-Cosma, E.; Chrisey, D. B. Mater. Sci. Eng., B 2010, 169, 106-110. doi:10.1016/j.mseb.2010.01.036

39. Grumezescu, V.; Socol, G.; Grumezescu, A. M.; Holban, A. M.; Ficai, A.; Truşcă, R.; Bleotu, C.; Balaure, P. C.; Cristescu, R.; Chifiriuc, M. C. Appl. Surf. Sci. 2013, 302, 262-267. doi:10.1016/j.apsusc.2013.09.081

40. Paun, I. A.; Moldovan, A.; Luculescu, C. R.; Staicu, A.; Dinescu, M. Appl. Surf. Sci. 2012, 258, 9302-9308. doi:10.1016/j.apsusc.2011.10.044

41. Cristescu, R.; Popescu, C.; Popescu, A. C.; Grigorescu, S.; Duta, L.; Mihailescu, I. N.; Caraene, G.; Albulescu, R.; Albulescu, L.;

Andronie, A.; Stamatin, I.; Ionescu, A.; Mihaiescu, D.; Buruiana, T.; Chrisey, D. B. Appl. Surf. Sci. 2009, 255, 5600-5604. doi:10.1016/j.apsusc.2008.09.047

42. Stamatin, L.; Cristescu, R.; Socol, G.; Moldovan, A.; Mihaiescu, D.; Stamatin, I.; Mihailescu, I. N.; Chrisey, D. B. Appl. Surf. Sci. 2005, 248, 422-427. doi:10.1016/j.apsusc.2005.03.060

43. Socol, G.; Preda, N.; Socol, M.; Sima, L.; Luculescu, C. R.; Sima, F.; Miroiu, M.; Axente, E.; Visan, A.; Stefan, N.; Cristescu, R.;

Dorcioman, G.; Stanculescu, A.; Radulescu, L.; Mihailescu, I. N. Dig. J. Nanomater. Bios. 2013, 8, 621-630.

44. Grumezescu, A. M.; Vasile, B. Ş.; Holban, A. M. Lett. Appl. NanoBioScience 2013, 2 (4), 120-123.

45. Xiao, C. D.; Shen, X. C.; Tao, L. Int. J. Pharm. 2013, 452, 227-232. doi:10.1016/j.ijpharm.2013.05.020

46. Saviuc, C.; Grumezescu, A. M.; Oprea, E.; Radulescu, V.; Dascalu, L.; Chifiriuc, C.; Bucur, M.; Banu, O.; Lazar, V. Biointerface Res. Appl. Chem. 2011, 1 (1), 15-23.

47. Saviuc, C.; Grumezescu, A. M.; Holban, A.; Chifiriuc, C.; Mihaiescu, D.; Lazar, V. Biointerface Res. Appl. Chem. 2011, 1 (2), 64-71.

48. Ladj, R.; Bitar, A.; Eissa, M. M.; Fessi, H.; Mugnier, Y.; Le Dantec, R.; Elaissari, A. Int. J. Pharm. 2013, 458, 230-241. doi:10.1016/j.ijpharm.2013.09.001

49. Gomaa, I. O.; Kader, M. H. A.; Salah, T. A.; Heikal, O. A. Drug Discoveries Ther. 2013, 7, 116-123. doi:10.5582/ddt.2013.v7.3.116

50. Naqvi, S.; Samim, M.; Abdin, M. Z.; Ahmed, F. J.; Maitra, A. N.; Prashant, C. K.; Dinda, A. K. Int. J. Nanomed. 2010, 5, 983-989. doi:10.2147/IJN.S13244

\section{License and Terms}

This is an Open Access article under the terms of the Creative Commons Attribution License

(http://creativecommons.org/licenses/by/2.0), which permits unrestricted use, distribution, and reproduction in any medium, provided the original work is properly cited.

The license is subject to the Beilstein Journal of Nanotechnology terms and conditions: (http://www.beilstein-journals.org/bjnano)

The definitive version of this article is the electronic one which can be found at:

doi:10.3762/bjnano.5.99 